\title{
summary
}

\section{No research evidence to support the prophylactic removal of pathology-free impacted third molars}

Song F, O'Meara S, Wilson P, Kleijnen J, Golder S. The effectiveness and cost-effectiveness of the prophylactic removal of wisdom teeth. NHS Centre for Reviews and Dissemination, University of York, November 1999, Report commissioned by the NHS HTA Programme on behalf of the National Institute for Clinical Excellence

Objective To summarise existing evidence on prophylactic removal of impacted wisdom teeth, in terms of the incidence of surgical complications associated with prophylactic removal and the morbidity associated with retention.

Data sources Update of a previous review with additional searches of MEDLINE (1984-1999), EMBASE (1984-1999), Science Citation Index, Cochrane Controlled Trials Register, The National Research Register, The Database of Abstracts of Reviews of Effectiveness, and the NHS Economic Evaluation Database plus additional paper and webbased sources.

Study selection Reviews or RCTs that considered surgical removal of unerupted or impacted third molars, either as prophylaxis or because of pathology reporting outcomes including pathology and/or symptoms associated with unerupted or impacted third molars or surgical outcomes were eligible for inclusion.

Results We identified 4682 references, of which 28 met the inclusion criteria. Two RCTs, 22 literature reviews and four decision analyses. Results from both RCTs suggested that prophylactic removal of third molars is unjustified (one trial provides preliminary data only). Methodological quality of the reviews was generally poor. Five reviews suggested only a weak association between retention of third molars and anterior crowding. Five reviews concluded that the prophylactic removal of third molars was unjustified. Nine reviews had no clear conclusion. One review (of poorer methodological quality) suggested that prophylactic removal of third molars is appropriate. The decision analyses indicated that retention of third molars was cost saving and more cost-effective compared with prophylactic removal of all impacted third molars. There are currently two ongoing RCTs, one in Denmark the other in the USA

Conclusion There is no reliable research evidence to support the prophylactic removal of pathology-free impacted third molars. Welldesigned RCTs with long-term follow-up are required in order to confirm this.

Address for reprints: The review is available on the web at: http:// server1.nice.org.uk/nice-web/Cat.asp?c=509

\section{Commentary}

The literature concerning the removal of impacted third molars is extensive, including documentation of morbidity associated with third molar surgery ${ }^{1-4}$, the pathology associated with retaining such teeth $^{5-8}$, and support for the theory that impacted teeth should be removed prophylactically at an early age $^{9-13}$. The indications for removal of impacted teeth when associated with pathology have been clearly established, universally endorsed and based on objective criteria ${ }^{14}$. The rationale for 'prophylactic odontectomy' is grounded in the theories of preventive and interceptive medicine.

To date, no long-term prospective studies have been performed that validate the benefit to the patient of retaining impacted teeth. When decision analysis methods have been used to attempt to determine either cost-benefit or risk-benefit ratios related to extraction or non-extraction of asymptomatic unerupted third molars, the data which give rise to assumptions and probabilities upon which these analyses are based, are of necessity derived from specific and limited populations and, as a result, can never be sufficiently complete to cope with all the variations needed to treat all individuals. Even if the data were available, one result could not be satisfactorily compared with another purely in terms of probability because of the familiar problem of trying to relate statistical significance to clinical relevance. Indeed, the serious flaw in many articles such as that by
Stephens et $a l^{15}$ results from basing conclusions solely on radiographic examination of a complex clinical event. Neither clinicians nor epidemiologists can make a diagnosis of acute pericoronitis solely from a radiograph.

No prospective, long-term study exists which definitely answers the question whether to extract or to deliberately retain asymptomatic third molar teeth. Such a study dealing with wisdom teeth, or for that matter any other surgical clinical problem, is highly unlikely to be successfully carried out in the foreseeable future. We must therefore rely on traditional medical methods of studying indications and contraindications in developing a diagnosis and treatment plan for each individual patient. 
A strong indication for removal of the impacted third molar should be complimented with a strong contra-indication to its retention. The inverse of this statement is also germane to the topic but little attention, to date, has been paid to it in the literature. It appears that as yet, for many patients, evidence to permit development of absolute indications and contra-indications for either deliberate retention or surgical removal of the asymptomatic impacted third molar is insufficient.

1. Belinfante L, Marlow C, Myers W, Rosenberg C. Incidence of dry socket complication in third molar removal. J Oral Surg 1973; 31:106-108.

2. Golberg $M$, Nemarich A, Marco W. Complications after mandibular third molar surgery: a statistical analysis of 500 consecutive procedures in private practice. JADA 1985; 111:277-279.
3. Osborn T. A prospective study of complications related to third molar surgery. J Oral Maxillofac Surg 1985; 43:767-769.

4. Sisk A, Hammer WB, Shelton DW, Joy ED Jr Complications following removal of impacted third molars: the role of the experience of the surgeon. J Oral Maxillofac Surg 1986; 44:855-859.

5. Dachi S. Survey of 3875 routine full mouth radiographs. A study of impacted teeth. Oral Surg 1961; 14:1165-1168.

6. Hinds EC, Frey KF. Hazards of retained third molars in older persons. JADA 1980; 101:246-250.

7. Laskin DM. Indications and contraindications for removal of the impacted tooth. Dent Clin North Amer 1969; 13:919-928.

8. Lytle JJ. Indications and contraindications for removal of the impacted tooth. Dent Clin North Amer 1979; 23:333346.

9. Henry H. Prophylactic odontectomy of the developing mandibular third molar. Am J Orthodont Oral Surg 1938; 24:72-79.
10. Hillin G. Indications for removal of impacted third molars at an early age. Am J Orthodont Oral Surg 1947; 33:30-33.

11. Ash M. A study of periodontal hazards of third molars. J Periodont 1962; 33:209-214.

12. Bruce RA, Frederickson GC, Small GS. Age of patients and morbidity associated with mandibular third molar surgery. JADA 1980; 101:240-245.

13. Kugelberg C. Periodontal healing two and four years after impacted lower third molar surgery. A comparative retrospective study. Int J Oral Maxillofac Surg 1990; 19:341345.

14. National Institutes of Dental Research and Office of Medical Applications, National Institutes of Health. Removal of third molars. NIH consensus conference summary $1979 ; 2: 65-68$.

15. Stephens R, Kogan S, Reid J. The unerupted or impacted third molar: a critical appraisal of its pathologic potential. J Can Dent Assoc 1989; 55:201-207.

David Precious Dalhousie University, Canada 